\title{
TOWARDS A CONTRACTION \& CONVERGENCE TARGET BASED ON POPULATION LIFE EXPECTANCIES SINCE 1960
}

\author{
Read, Paul A - Senior Research Fellow \\ Monash Sustainability Institute \\ Postal - Monash University, VIC 3800, Australia \\ Monash Science Centre, Building 74 \\ Clayton Campus, Wellington Road, Clayton \\ Telephone: +61 399020239 \\ Fax: +61399059348 \\ Email: paul.read@monash.edu \\ Stanley, Janet R - Chief Research Officer \\ Monash Sustainability Institute \\ Monash University, Building 74, Wellington Road \\ Clayton, VIC, 3800, Australia \\ T: +613 99020737 \\ M: +61 (0)418 407248 \\ Janet.Stanley@msi.monash.edu.a
}

\section{Vella-Brodrick, Dianne A - Senior Lecturer}

School of Psychology and Psychiatry, General Office

Room 405, Building 17

Clayton Campus

Monash University

Victoria 3800 , Australia

Tel: +61 399032542

Fax: +61 395946499

E-mail: Dianne.Vella-Brodrick@monash.edu

\section{Griggs, Dave J - Professor}

CEO ClimateWorks Australia

Director Monash Sustainability Institute

Postal - Monash University, VIC 3800, Australia

Monash Science Centre, Building 74

Clayton Campus, Wellington Road, Clayton

Telephone: +61 399020239

Fax: +61 399059348

Email: dave.griggs@monash.edu

www.monash.edu/research/sustainability-institute/

Introduction 
As yet, there is no target for carbon emissions (CE) empirically established for human development. Respected economists have made educated guesses ranging 2-6 tonnes per capita (Stern, 2008; Ekins, Meyer \& Shmidt-Bleek, 2009; Hansen , 2009; Shmidt-Bleek, 2009; Garnaut, 2011), but the issue spans climate science, public health, economic development and human ethics under the umbrella of global warming (e.g. Stern, 2006; Frumkin, McMichael \& Hess, 2008). Copenhagen achieved multilateral agreement on a limit of $\leq 2^{\circ} \mathrm{C}$ warming, beyond which it was agreed there would be unacceptable impacts on biosocial systems (McGray, 2010). This then creates an upper ceiling of total allowable emissions based on constraining the atmospheric concentrations of carbon dioxide (Hare \& Meinshausen, 2006). Leading up to 2050, the strongest modelling was developed by Meinshausen and colleagues (2009), whose seminal work demonstrated a $25 \%$ risk of exceeding $2^{\circ} \mathrm{C}$ with a total cumulative emissions budget of a trillion tonnes (1000 Gigatonnes, Gt) from 2000-2050. Using the same model, risk is reduced on the smaller budget of 750Gt suggested by Hansen and colleagues (2008). The problem confronting both is that the world had already used up 234Gt from 2000-2006 (Meinhausen et alia, 2009).

As of 2011, global emissions peaked at a record high, prompting the International Energy Agency 's Chief Economist Fatih Birol to warn "the door to a $2^{\circ} \mathrm{C}$ trajectory is about to close" (IEA, 2012, p1). Given current growth (see IEA, 2012), close to half the entire Hansen budget will have been used up by mid-next year (2013), leaving much smaller rations for the next four decades. Delayed international action then makes the rate of change in the future much steeper and harder to adapt to for both advanced and developing economies.

This raises an ethical dilemma in terms of both international and intergenerational equity because in order to satisfy the one it must undermine the other. This is because we are close to reaching the precipice of exceeding the $2^{\circ} \mathrm{C}$ limit without allowing the bulk of the world's developing nations to reach parity with a minority of wealthier, carbon-intensive economies. Moreover, because global emissions (IEA, 2010) and population (UN, 2011) are both steadily growing, the yearly amount of allowable emissions compound the ethical problems yet to be confronted.

One principle that tries to balance the dilemma is Contraction and Convergence (C\&C). Although the implementation rate was a stumbling block at Copenhagen and Durban (Meyer \& O'Connell, 2010), C\&C begins to provide a fair platform for multilateral negotiations. This principle (see Global Commons Institute, 1996) first assumes that global CE will negatively impact human and planetary health in the longer term and so must be 'contracted' if we care about the likely impact on younger generations (e.g. Sherwood \& Huber, 2010). If it were not a normal public good, this would not present a problem, but because CE is tied to economic development (York, Rosa \& Dietz, 2003; Rosa, York \& Dietz, 2004), it means any pursuit of global contraction could result in recession or depression among advanced economies. This was suggested when the Global Financial Crisis (GFC) reduced world emissions (see Jotzo et alia, 2012). Although there is resistance to the idea of contraction, whether by a Pigovian tax or a trading scheme (Garnaut, 2011), climate science suggests we have no choice. The alternative could be resource and energy wars and further destruction of ecologies subserving human survival (e.g. Parry et alia, 2004; Thomas et alia, 2004; Malcolm et alia, 2006). The second element of $C \& C$ is 'convergence', where every nation must be granted an equal portion of emissions per capita under a constrained global budget $(\mathrm{GCl}, 1996)$. This applies the same ethical principle of unity across nations as contraction applies across generations (see Stern, 2006; 
Nordhaus, 2007). Together, the two principles of C\&C try to balance the carbon budget across every living person, both now and in the future.

Having defined C\&C, we can now look at the implications of the climate science. Hansen's conservative budget of 750Gt would mean around 450Gt will be subtracted from the cumulative budget by mid-next year, leaving 300Gt remaining. Given a global population of 6.8 billion in 2011, that leaves a C\&C target of only about 1.3 tonnes per capita for every year leading up to 2050 . The more optimistic Meinshausen budget allows 1.8 tonnes for a population heading towards 9.2 billion by 2050 (UN, 2011), roughly matching Stern's original suggestion of 2 tonnes per capita in 2008 (Stern, 2008). The problem is that both are a much greater challenge to advanced economies than the global average of 6 tonnes per capita. They also suggest the current rate of technological development aimed at decoupling growth from CE (see Steinberger et alia, 2012) will not avoid the $2{ }^{\circ} \mathrm{C}$ limit. It appears widespread and dramatic mitigation and adaptation is inevitable, that advanced economies must contract their emissions and developing countries should not pursue parity at the upper levels.

The current paper explores what these $C \& C$ targets might mean for human $L E$, hoping there might be a more optimistic outcome. Before describing the methods, we outline evidence suggesting economic growth might not offer positive, monotonic and linear returns on human welfare in the first place. In fact, there may be reasons why developing nations should not expect linear gains in human welfare from carbonised growth beyond a certain limit. If stable, this limit might offer a more optimistic C\&C target up to 2050.

\section{Human Health and Happiness}

In the mid-1970s, two stylised curves were identified across countries that suggested national wealth can only achieve so much in terms of human outcomes. Preston found LE and GDP per capita both rise until they reach a certain point, after which no amount of wealth seems to make much difference (Preston, 1975). A year earlier, Easterlin (1974) found the same curve emerged for human wellbeing. These curves offer cross-validation by virtue of their different methods wellbeing is based on survey data of how people subjectively feel about their life circumstances in different countries (see Diener \& Suh, 2000) and LE is an objective average based on the relevant year's reported death rates weighted by population and age (CSDH, 2008). Both have problems but their cross-validation partly obviates the need to explore them here. They suggest no matter what the outcome metric, wealth reaches a threshold beyond which it has little or no impact on health and wellbeing across countries. Note the same occurs within countries and across years. Easterlin (2005) demonstrated wellbeing in the USA, European Union and Japan remained mostly stagnant over the past 50 years despite up to 300-fold increases in GDP per capita. A similar trend occurs for LE, with minor gains accumulating each year despite changes in national and global wealth (World Bank Report, 1993).

The literature has not yet reached consensus on the meaning of these curves but there is converging support across disciplines that wealth satisfies basic human needs until it reaches a threshold beyond which returns are diminishing, zero or even negative, resembling a classic growth curve (Diener et alia, 1993; Inglehart, 1997; Frey \& Stutzer, 2002; Oswald, 2005). Controversies will be discussed later because they echo concerns about the environmental Kuznet's curve (for an overview, see Stern, 2004). In the meantime, we simply note that 'human needs' is a concept 
fundamental to the Brundtlandt definition of sustainability (Brundtlandt Commission, 1987), and if the bulk of ecological impact emerges from a minority of wealthy countries that achieve less and less in terms of human outcomes, it raises some serious questions about development and sustainability.

\section{Development and Sustainability}

Stepping backwards, we revisit the United Nations Human Development Index (UNHDI), a composite of LE, GDP per capita and education that weights each metric as if equally valued by all people (see Haq, 1995). If we assume that wealth beyond threshold offers little in terms of LE but continues to have a negative ecological impact, then gains in the UNHDI can only be made long after wealth ceases to have any real impact on human health. A world pursuing an improved HDI would then rely on greater ecological impact that constrains the longevity of future generations, making the UNHDI inherently unsustainable. It was Veenhoven (1996), a wellbeing researcher, who pointed out that the UNHDI mixes outputs such as LE with metrics that are usually viewed as inputs. Veenhoven suggested a universally valued output could multiply LE by subjective wellbeing to create the Happy Life Year (HLY), similar in logic to the Disability-Adjusted Life Year (Murray \& Lopez, 1996). HLY is now used by the New Economics Foundation as the numerator for the Happy Planet Index (NEF-HPI) when dividing it by Ecological Footprint (EF) as the denominator (Marks et alia, 2006). The NEF-HPI then becomes an efficiency metric that bypasses GDP altogether, avoiding issues of parity, utility, income, inflation, consumption, production, non-market activities, bartering, volunteerism and household production of labour (e.g. Robinson, 1962; Folbre, 2008).

The HPI recently nominated Costa Rica as the world's most sustainable country because it achieves a 'long and happy life' despite lower ecological impact than wealthier countries (Abdallah et alia, 2009). This raises the question of whether the rest of the world could pursue parity. The problem is that most are small island nations that have geographic advantages in terms of tourism, so unless there are also cultural patterns of sustainable living that the rest of the world might follow, this endeavour plunges the issue back into the realm of economics, trade and comparative advantage. There is also another problem with the NEF-HPI that tends to push it back into economic territory.

Wealth beyond threshold is thought to have little, if any, effect on wellbeing because people rate their wellbeing relative to the resources enjoyed by others in their cultural milieu. This means any increase in an already wealthy country hinges on consuming more than another comparatively wealthy person. As the baseline wealth of the country rises, so do expectations - so there is ultimately no net gain in subjective wellbeing beyond threshold in the longer term, even though ecological impact continues to rise. The pursuit of happiness, if relative (first suggested by Duesenberry, 1949), then becomes a 'zero sum game' that drives the Hedonic Treadmill (Brickman \& Campbell, 1971). The end result is that the NEF-HPI, by using subjective wellbeing as a multiple of the output, might be just as unsustainable as the UNHDI.

Even in earlier surveys by Cantril (1965), people in poor countries said they would be happier if only they had a goat whereas people in wealthy countries wanted a boat. Their desires were culturally relative even though their actual satisfaction tends to be short-lived before settling down to what has been described as a genetic, or homeostatic, set-point for human wellbeing (Gullone \& Cummins, 2002). Moreover, subjective wellbeing is measured on an ordinal Likert scale with no true zero point, so is statistically shaky when multiplied by LE and then compared to wealth or ecological impact. By 
contrast, the current paper uses LE as a universal human output because it is a ratio scale with a true zero point that also offers:

1. A harmonised formula that equally applies across time and countries (HMD, 2011)

2. A universally valued outcome that transcends cultures and disciplines (CSDH, 2008)

3. A proxy of human survival that resonates with the definition of needs (Brundtlandt, 1987)

4. A long heritage of comparable data going back to $18^{\text {th }}$ Century France (HMD, 2011)

5. A wealth of literature that links longevity to paleo-anthropological data (Steckel, 1983)

6. A wealth of laboratory data from medicine, public health and psychology

These advantages allow tests of one key metric that, unlike wealth or wellbeing, is less affected by subjective cultural relativism and much more founded in basic human survival. This means it is equally important across countries and time regardless of cultural contexts. As a consequence, it is one metric that should be just as relevant to future generations as it was in the past, and so a more fundamental metric of development and sustainability in terms of human needs.

\section{Comparability across Time}

We argue the NEF-HPI would be more sustainable if it dropped subjective wellbeing because it is polluted by economic and cultural influences that change across time and contexts. On a practical level, wellbeing also constricts the sample size across time and countries because it relies on more recent data from Gallup (2006) and the World Values Survey. By the time it stretches back to 1960, sample size is reduced from 200 to 25 countries capturing the OECD - an unrepresentative group that ignores poorer countries and masks the broader curve (Abdallah et alia, 2009). A similar problem emerges for the denominator of the NEF-HPI. Although EF is one of the most validated accounting measures when tested against objective measures like satellite imagery (Sutton, 2003; Sutton et alia, 2009), it is more complicated to compute than our preferred metric of CE and so remains less represented across time and countries (Wackernagel \& Rees, 1996). In our defence, the NEF-HPI often uses CE as a proxy for EF, which is justifiable given that EF partly relies on CE data itself. Whilst the current paper would prefer $E F$, stability across time and countries requires we revert to CE to bypass GDP (as per the HPI) whilst directly linking to accepted carbon budgets.

\section{Using Proxy Variables}

This leaves us with two national indicator variables that have no mechanistic basis for being causally linked:

1. Human health as an 'output' variable (LE)

2. Ecological impact as an 'input' variable (CE)

Even when seeking an instrumental variable like the recent volcanic eruption in Iceland, there is no evidence that CE per se has any direct impact on localised LE (Carlsen et alia, 2012). At the aggregate level, both are merely proxy indicators of human and planetary health that treat the social unit, here the nation state, as a big 'black box' in which thousands of omitted variables operate in complex pathways spanning wealth, equity, growth, production, distribution and consumption of everything from food and medicine to debt and education. Although we use regression techniques, we do not attempt to model a functional form that controls for omitted variables. Rather, the statistical rationale of this paper is more mercenary as it exploits an econometric regression 
technique with the sole aim of interpolating a stable empirical threshold at the maximum of LE. In this sense, it suffers all the problems confronted by the environmental Kuznet's curve (see Stern, 2004) and would deserve just as much caution were it not for the fact that this paper has a very different aim.

It is not so much the explanatory form of the curve that is of key interest as the threshold that can be calculated across time. Using pure frontier regression goes some way towards eliminating the gross effects of omitted variables such as war, infection and extreme inequity but this was not the original reason for its use. It was in analysing the datasets of the NEF-HPI that the authors noticed its efficiency metric, without further adjustments, made some of the most 'miserable' (and inequitable) countries appear more sustainable. To handle the first problem, the NEF-HPI added a pair of constants to the numerator and denominator, which shifted the target upwards towards more acceptable human outcomes, first represented by Vanuatu (Marks et alia, 2006) and then Costa Rica (Abdallah et alia, 2009). Yet this still glossed over the need for an empirical target in terms of human outcomes, forcing the NEF to develop a 'Traffic Light' system colour-coding all the key metrics and allowing readers to make their own value judgements about the competing interests of wellbeing, longevity and ecological impact. Once again, this resonates with another problem confronting the UNHDI, which keeps shifting its own definitions for development based on arbitrary statistical manoeuvres, especially as many more countries shift from the 'developed' to the newly created 'highly developed' categories.

\section{Pure Frontier Regression}

When looking at the NEF-HPI, the authors of the current paper sought a method that would allow the data to speak for itself in terms of generating an empirical threshold that transcended the use of arbitrary constants or categories of development. The rationale that emerged was based on pure frontier regression which we expect will ultimately offer much richer information than the composite efficiency metric of the HPI.

Traditionally, frontier regression models "explain boundary, frontier or optimal behaviour rather than average behaviour as in ordinary regression models" and are "desirable alternatives in many circumstances" (Troutt, Hu, Shanker \& Acar, 2001, p.1). In such circumstances, it is not the average that is sought as the target outcome so much as the best possible benchmark at the upper extremes of the curve, sometimes called the 'ceiling'. In a much removed context, frontier regression was first raised by Farrell (1957) and was later applied by Aigner \& Chu (1968) using a Cobb-Douglas production function looking at profit maximisation among firms. This identified the maximum boundary of the key output variable achievable for every level of input (Sieford \& Thrall, 1990; see also Coelli et alia, 2005). In these early approaches, the aim was to explain how factors of production could be more efficiently exploited to maximise performance in terms of profit. For this reason, their focus was on capturing and explaining the error variance below the ceiling, stimulating concepts of productive efficiency controlled for error variance below the curve. This led to stochastic frontier regression where the error was split between a half-normal term based on curve variation with the remainder being an estimate of total inefficiency - the key dependent variable in explanatory models. Many more complex forms later emerged such as Data Envelopment Analysis, with some methods being applied to issues of income (Sen, 1981), health expenditure (Evans et alia, 
2000), life expectancy (Dietz, Rosa \& York, 2009) and the Millennium Development Goals (Jayasuriya \& Wodon (2003).

Where the current paper diverges is that no explanatory model is needed to empirically estimate a carbon threshold. Because maximising LE is one of few human outcomes that is universally valued across cultures (CSDH, 2008), it argues for the use of the frontier rather than the average as a more appropriate form of analysis. But rather than attempting to decompose and explain the variance below the ceiling (as in Dietz, Rosa \& York, 2009), this work focuses on validating the term of technical efficiency as a stable threshold across time. So its main challenge is to validate stability, where the error term becomes horizontal across time rather than vertical within time. The functional form of pure frontier regression used by this paper is given by the following formula adapted from Troutt and associates (2001):

$$
y_{j}=\beta_{0}+\beta_{1} x_{j}+\beta_{2} x_{j}^{2}+\beta_{3} x_{j}^{3}-\omega_{j}
$$

where $y_{j}=\ln (\mathrm{CE} / \mathrm{Cap})$ for Year $j, x_{j}=\left(\right.$ Year-2000) and $\omega_{j}=$ a non-negative error for Year $j$

The optimal LE can then be interpolated from the curve formulae for every year from 1960-2007. To test horizontal stability, the paper borrows from psychometrics, using split-half reliability. It then tests the variance across time to see whether there is a stable threshold of CE that matches optimal LE. Regardless of causality, the results empirically prove, by appealing to falsification, that greater $\mathrm{CE}$ is not needed to improve human outcomes. This is slightly more optimistic than economic studies might assert under carbon budgets leading up to 2050 .

\section{METHODS}

\section{Data Sources \& Cleaning}

The World Bank provides data from 1960-2007 for 205 countries. Life expectancy at birth (LE) is the number of years a newborn infant would live if prevailing patterns of mortality at the time of birth were to stay the same, based on death rates at each age in each year weighted by population cohorts to derive the average age at death for the whole population (based on male and female life expectancies at birth from the United Nations Population Division, 2009). For CE, 195 countries are included, estimated from the burning of fossil fuels plus the manufacture of cement, derived from the United States Carbon Dioxide Information Analysis Center (2009). They include solid, liquid, gas fuels and gas flaring but not equivalent emissions $\left(\mathrm{CO}_{2} \mathrm{e}\right)$. Datasets are matched against one another in each year, eliminating missing cells and leaving a total sample of up to 192 countries from 19602007. Data is rounded to the third decimal place.

\section{Procedures}

For each year, LE and CE per capita are aligned by country and then ranked by LE from highest to lowest. The pure frontier formula is applied for each year to extract the upper boundary of LE. This captures the highest observable 'output' (LE) at every level of observable 'input' (CE/cap) and generates a much smaller sample that is outside the control of the researcher. The strongest curve is fitted to minimise error in every available year from 1960-2007. Using GNU R, F tests are reported for 1000 simulations of cubic versus quadratic curves, with confidence intervals for the interpolated optima. The stability of the value of CE per capita (CE/cap) that interpolates optimal LE can then be 
ascertained stretching back to 1960. Additionally, the curve formula for 1960 can be used to predict the actual values in 2007 as a test of predictive validity. As a preliminary test of internal validity, these years are also randomly split into two subsamples before the frontier procedure is applied, allowing the quadratic formula from one split sample within that year to predict the other, the correlation being the usual test of split-half reliability as borrowed from psychometrics.

\section{RESULTS}

As would be expected, average LE is higher in 2007 than 1960 but the association with CE/cap follows the same trend in both years (see Figure 1). By converting input to the natural logarithm (In) of the CE/cap term, the curve is more easily viewed. For 2007, LE increases from Zimbabwe up to a threshold that declines from Costa Rica and Japan, achieving the highest LE (83 years), down to Qatar ( $\mathrm{N}=185$ ). The same pattern is evident in the data sampled in 1960 rising from Afghanistan to Switzerland and Norway (74 years) and then down to Kuwait and Luxembourg ( $N=155)$. Note the optimum shifts from Norway to Japan, suggesting it is not an artefact of unchanging advantages enjoyed by a single country. The optimum LE for 2007 is 77 years on 19 tonnes compared to 68 years on 12 tonnes for 1960. Because the curve generated from the average of the full dataset fails to match the observed optima for $L E$, it demonstrates distortions in the curve. These are now eliminated using the frontier.

\section{INSERT FIGURE ONE}

Figure 1. The relationship between LE and InCE/Cap using raw data (above) and the frontier (below).

For both 1960 and 2007, the frontier renders the curves depicted in the lower portion of Figure 1, capturing the highest LE's achieved across the whole datasets. The optimal LE calculated by the frontier curve for 1960 is 73 years on 7 tonnes CE/cap, much closer to the observed maximum of 74 years for Norway. Likewise, the optimal LE predicted by the 2007 curve is 82 years on 9 CE/cap, again much closer to Japan's observed maximum of 83 on 10 tonnes. Predictive validity is tested using the frontier formula in 1960 to predict the observed results in 2007, $r^{2}=0.95(p<0.05)$. Splithalf reliability was $r^{2}=0.96(p<0.05)$ for 1960 and $r^{2}=0.92(p<0.05)$ for 2007. $1000 \mathrm{GNU}$ simulations of cubic versus quadratic curves supports the third order quadratic formula across every year (as did robust regression). Table 1 shows each of the yearly frontier curves is significant ( $p>0.001)$. This provides $\mathrm{F}$ tests based on the third order curve formula, the corresponding $p$ values and the $95 \%$ Confidence Intervals of the interpolated optima.

Table 1. Testing quadratic curve fitting of the frontier plus stability across time

\begin{tabular}{|c|c|c|c|c|c|c|c|c|c|c|c|}
\hline & \multicolumn{4}{|c|}{ Frontier Curve Function } & \multirow[t]{2}{*}{$r^{2}$} & \multirow[t]{2}{*}{ F Value } & \multirow[t]{2}{*}{ P Value } & \multirow[t]{2}{*}{$\mathrm{LE}_{\max }$} & \multirow[t]{2}{*}{$\mathrm{CE}_{\max }$} & \multicolumn{2}{|c|}{ Confidence Intervals } \\
\hline & B Zero & B 1 & B 2 & B 3 & & & & & & 0.025 & 0.975 \\
\hline 1960 & 67.09 & 11.92 & -4.89 & $\begin{array}{l}-1.74 \\
\end{array}$ & 0.97 & 218.87 & 0.00 & 72.62 & \begin{tabular}{|l|}
6.93 \\
\end{tabular} & 5.27 & 10.38 \\
\hline 1961 & 68.02 & 11.63 & -6.24 & -2.66 & 0.94 & 103.90 & 0.00 & 72.21 & 4.54 & 3.63 & 6.11 \\
\hline 1962 & 68.75 & 11.20 & -5.83 & -1.92 & 0.95 & 120.18 & 0.00 & 73.08 & 5.13 & 4.01 & 6.77 \\
\hline 1963 & 68.98 & 8.95 & -5.84 & -1.00 & 0.93 & 90.33 & 0.00 & 72.06 & 4.53 & 3.23 & 6.13 \\
\hline 1964 & 67.42 & 12.23 & -4.75 & -2.20 & 0.92 & 74.37 & 0.00 & 73.04 & 6.61 & 5.04 & 8.59 \\
\hline 1965 & 67.70 & 12.48 & -4.77 & -2.07 & 0.92 & 83.00 & 0.00 & 73.60 & 6.99 & 5.24 & 9.12 \\
\hline 1966 & 68.61 & 10.35 & -4.91 & -1.56 & 0.92 & 54.12 & 0.00 & 72.96 & 5.90 & 4.32 & 8.37 \\
\hline 1967 & 69.36 & 9.72 & -4.95 & -1.49 & 0.93 & 63.65 & 0.00 & 73.24 & 5.45 & 4.08 & 7.20 \\
\hline 1968 & \begin{tabular}{|c|}
68.52 \\
\end{tabular} & \begin{tabular}{|c|}
11.78 \\
\end{tabular} & -5.29 & $\begin{array}{l}-2.02 \\
\end{array}$ & 0.91 & 48.69 & 0.00 & \begin{tabular}{|l|}
73.53 \\
\end{tabular} & 5.91 & 4.31 & 8.40 \\
\hline
\end{tabular}




\begin{tabular}{|c|c|c|c|c|c|c|c|c|c|c|c|}
\hline 1969 & |69.80 & 8.44 & \begin{tabular}{|c|}
-5.08 \\
\end{tabular} & -0.89 & 0.89 & 35.02 & 0.00 & 72.92 & 5.02 & 3.07 & 7.65 \\
\hline 1970 & 68.14 & 12.08 & \begin{tabular}{|l|}
-4.66 \\
\end{tabular} & \begin{tabular}{|c|}
-1.80 \\
\end{tabular} & 0.95 & 120.88 & 0.00 & \begin{tabular}{|l|}
73.93 \\
\end{tabular} & 7.29 & 5.84 & 9.34 \\
\hline 1971 & 69.94 & 8.23 & -4.77 & -0.80 & 0.97 & 210.75 & 0.00 & 73.09 & 5.35 & 4.22 & 6.65 \\
\hline 1972 & 69.21 & 9.61 & -3.81 & -1.43 & 0.93 & 90.75 & 0.00 & 73.74 & 7.10 & 5.44 & 8.94 \\
\hline 1973 & 69.24 & 9.88 & \begin{tabular}{l|l|}
-4.12 \\
\end{tabular} & -1.24 & 0.96 & 138.68 & 0.00 & 73.91 & 7.30 & 5.81 & 9.02 \\
\hline 1974 & 70.96 & 7.83 & -4.81 & -0.47 & 0.98 & 229.87 & 0.00 & 73.94 & 5.44 & 4.15 & 7.22 \\
\hline 1975 & 70.30 & 11.13 & -4.95 & -1.63 & 0.97 & 220.57 & 0.00 & 75.20 & 6.38 & 5.37 & 7.58 \\
\hline 1976 & \begin{tabular}{|c|}
69.18 \\
\end{tabular} & 12.12 & \begin{tabular}{|c|}
-4.54 \\
\end{tabular} & \begin{tabular}{|c|}
-1.93 \\
\end{tabular} & 0.95 & 117.81 & 0.00 & 75.02 & 7.27 & 5.70 & 10.19 \\
\hline 1977 & 70.20 & 10.40 & -5.30 & -0.91 & 0.97 & 275.96 & 0.00 & 74.67 & 6.48 & 5.26 & 8.14 \\
\hline 1978 & 69.84 & 11.32 & -4.91 & -1.18 & 0.97 & 250.33 & 0.00 & 75.20 & 7.52 & 6.17 & 9.78 \\
\hline 1979 & 69.68 & 12.43 & -4.70 & -1.73 & 0.97 & 225.04 & 0.00 & 75.80 & 7.73 & 6.20 & 10.03 \\
\hline 1980 & 69.54 & 13.54 & $\begin{array}{l}-4.92 \\
\end{array}$ & -2.32 & 0.95 & 115.07 & 0.00 & 76.06 & 7.18 & 5.59 & 9.41 \\
\hline 1981 & 72.26 & 10.36 & -5.75 & -1.28 & 0.93 & 54.84 & 0.00 & 76.26 & 5.31 & 3.23 & 7.74 \\
\hline 1982 & 72.93 & 10.54 & $\begin{array}{l}-6.02 \\
\end{array}$ & -1.45 & 0.93 & 57.43 & 0.00 & 76.86 & 5.00 & 3.49 & 7.06 \\
\hline 1983 & 71.72 & 12.18 & -5.84 & -2.20 & 0.93 & 71.09 & 0.00 & 76.64 & 5.45 & 3.99 & 8.06 \\
\hline 1984 & 72.32 & 12.68 & \begin{tabular}{|l|}
-6.03 \\
\end{tabular} & -2.40 & 0.94 & 76.37 & 0.00 & 77.44 & 5.40 & 4.12 & 7.17 \\
\hline 1985 & 71.87 & 14.75 & -5.54 & -3.19 & 0.94 & 82.98 & 0.00 & 78.50 & 6.18 & 4.78 & 8.58 \\
\hline 1986 & 72.55 & 11.63 & -5.30 & -2.03 & 0.94 & 80.16 & 0.00 & 77.44 & 5.79 & 4.26 & 7.98 \\
\hline 1987 & 72.59 & 9.55 & -5.00 & -0.81 & 0.97 & 156.50 & 0.00 & 76.61 & 6.30 & 4.84 & 8.78 \\
\hline 1988 & 73.32 & 10.34 & \begin{tabular}{|l|}
-4.61 \\
\end{tabular} & -1.96 & 0.96 & 119.46 & 0.00 & 77.65 & 5.71 & 4.63 & 7.54 \\
\hline 1989 & 73.69 & 10.29 & \begin{tabular}{|c|}
-4.79 \\
\end{tabular} & -1.81 & 0.95 & 69.51 & 0.00 & 77.95 & 5.66 & 4.23 & 7.90 \\
\hline 1990 & 75.39 & 3.08 & -2.11 & 0.21 & 0.89 & 28.36 & 0.00 & 76.61 & 6.78 & 0.26 & 34.40 \\
\hline 1991 & 75.38 & 8.38 & -3.35 & -2.16 & 0.96 & 56.11 & 0.00 & 78.87 & 5.40 & 4.39 & 6.48 \\
\hline 1992 & 74.84 & 5.23 & -2.84 & -0.36 & 0.91 & 36.58 & 0.00 & 77.02 & 6.29 & 2.78 & 28.23 \\
\hline 1993 & 73.78 & 5.72 & \begin{tabular}{|c|}
-2.64 \\
\end{tabular} & -0.40 & 0.89 & 34.07 & 0.00 & 76.50 & 7.97 & 3.97 & 33.80 \\
\hline 1994 & 74.96 & 7.37 & \begin{tabular}{|c|}
-3.56 \\
\end{tabular} & -0.81 & 0.95 & 65.24 & 0.00 & 78.16 & 6.46 & 4.37 & 12.30 \\
\hline 1995 & 73.71 & 11.14 & -4.28 & -1.66 & 0.98 & 245.46 & 0.00 & 79.07 & 7.33 & 6.29 & 9.07 \\
\hline 1996 & 73.56 & 13.81 & $\begin{array}{l}-4.57 \\
\end{array}$ & -2.56 & 0.97 & 153.81 & 0.00 & 80.43 & 7.44 & 6.27 & 8.90 \\
\hline 1997 & 74.89 & 11.25 & \begin{tabular}{|l|}
-4.70 \\
\end{tabular} & -1.56 & 0.92 & 48.39 & 0.00 & 80.11 & 6.98 & 5.06 & 10.73 \\
\hline 1998 & 74.15 & 13.19 & \begin{tabular}{|l|}
-4.76 \\
\end{tabular} & -2.10 & 0.92 & 53.31 & 0.00 & 80.65 & 7.53 & 5.44 & 11.92 \\
\hline 1999 & 73.54 & 14.92 & \begin{tabular}{l|l}
-4.80 \\
\end{tabular} & -2.68 & 0.93 & 65.95 & 0.00 & 81.13 & 7.78 & 5.89 & 12.19 \\
\hline 2000 & 72.94 & 15.84 & -4.76 & -2.69 & 0.93 & 76.00 & 0.00 & 81.39 & 8.51 & 6.63 & 12.29 \\
\hline 2001 & 73.90 & 14.87 & \begin{tabular}{|c|}
-4.78 \\
\end{tabular} & -2.71 & 0.96 & 131.25 & 0.00 & 81.44 & 7.71 & 6.47 & 9.95 \\
\hline 2002 & 74.84 & 13.82 & -5.50 & -2.15 & 0.98 & 236.99 & 0.00 & 81.29 & 6.94 & 5.98 & 8.68 \\
\hline 2003 & 75.86 & 11.43 & $\begin{array}{l}-6.00 \\
\end{array}$ & -0.74 & 0.98 & 241.62 & 0.00 & 80.79 & 6.69 & 5.24 & 9.81 \\
\hline 2004 & 74.28 & 14.36 & -4.99 & -2.00 & 0.95 & 102.76 & 0.00 & 81.71 & 8.40 & 6.23 & 12.60 \\
\hline 2005 & 74.99 & 12.90 & \begin{tabular}{|l|}
-4.80 \\
\end{tabular} & -1.40 & 0.96 & 110.57 & 0.00 & 81.72 & 8.91 & 6.63 & 12.93 \\
\hline 2006 & 75.12 & 13.71 & -5.16 & -1.73 & 0.96 & 143.89 & 0.00 & 82.02 & 8.15 & 6.20 & 11.56 \\
\hline 2007 & 75.21 & 13.87 & \begin{tabular}{|l|}
-5.03 \\
\end{tabular} & $\begin{array}{l}-1.93 \\
\end{array}$ & 0.96 & 146.95 & 0.00 & 82.21 & 8.06 & 6.56 & 10.43 \\
\hline Mean & 71.77 & 11.14 & $\begin{array}{l}-4.82 \\
\end{array}$ & -1.66 & 0.94 & & & 76.80 & 6.59 & 4.88 & 10.46 \\
\hline SD & 2.65 & 2.61 & 0.85 & 0.72 & 0.02 & & & 3.17 & 1.11 & 1.25 & 5.97 \\
\hline
\end{tabular}

As can be traced from Table 1, the mean of the predicted optima across all years is $6.6 \mathrm{CE} / \mathrm{cap}$. Whereas LE steadily increases across time at a rate of 2.5 months per year $\left(r^{2}=0.99, p<0.005\right)$, the CE that maximise LE does not significantly change. Figure 2 now contextualises the optimal LE plus Confidence Intervals against the highest CE/cap in each year. Although pure frontier regression is notoriously vulnerable to outliers, the consistency across time is powerfully supported outside of 1990, 1992 and 1994, where Namibia was an outlier based on its divergence from the frontier.

\section{INSERT FIGURE TWO}

Figure 2. CE/cap that optimises LE is lower across 48 years than maximum CE/cap

From 1960 until 2007, 88 countries achieve the frontier. Costa Rica retains its position at lower levels of CE for 41 years. Among lower levels of CE, Vietnam, Cuba and Malta do extremely well but China and India fail to reach the frontier in any given year. By contrast, countries that reach the 
frontier at higher levels of CE include Canada and Hong Kong (39 years), the United States (34 years), Japan (33) and Luxembourg (28). Countries like Qatar, Kuwait, United Arab Emirates and Bahrain achieve the frontier for many years but with low LE and much higher CE. Australia reaches the frontier across 18 years but always emits more than the predicted optimum.

\section{DISCUSSION}

This paper presents a stable albeit stylised curve that challenges the idea that greater carbonisation is needed for raising or sustaining average aggregate longevity. It suggests better health outcomes might be achieved by countries where CE is much lower than pursued by many advanced economies. Confidence intervals for $6.6 \mathrm{CE} / \mathrm{cap}$ that maximise LE are tight for all except three years in the 1990s where outliers may have distorted the curve. But because this trend is replicable since 1960, it might also apply towards 2050, softened by background increases in LE that might add up to 9 years in 2050 based on the trend since 1960. On top of this, many more countries might decouple growth from carbonised energy sources via technological innovation, greater efficiencies and renewable energy sources. This is already being led by Northern European and developing countries like China.

When using the frontier rather than the average, there is also a consistent loss of LE at higher emissions in each year. Although this might be challenged by planned analyses, some studies are beginning to confirm this trend (Bloomberg \& Aggarwala, 2008) whereas others hint that such an effect might emerge from over-consumption at higher levels of CE (Edwards and Roberts, 2010). On the production side, there is already much evidence that industrialisation is antithetical to human wellbeing and family cohesion; rates of stress, depression, accidents, suicide and drug addiction (e.g. Max-Neef, 1995; Zolatas, 1981; Eckersley, 2006; Hamilton \& Denniss, 2005; Jackson, 2009; Bradshaw et alia, 2007; Stevenson \& Wolfers, 2009). This idea is not new; it has a theoretical heritage spanning human development (Sen, 1999), the economic health gradient (Lopez et alia, 2006) and the health co-benefits of climate change mitigation (Frumkin, McMichael \& Hess, 2008).

Moreover, the curve reported in this paper mirrors the shape emerging for more basic human needs like food consumption, which, by most analyses, accounts for about one third of global CE (Stern, 2006; Vermeulen et alia, 2012; Thornton et alia, 2012). Like CE itself, food consumption is inequitably distributed across the economic health gradient where $16 \%$ of the world's people are starving (causing half of all child deaths below the age of five; WHO, 2000) and $20 \%$ are obese or overweight, their diets now directly linked to higher CE (UNFAO, 2010; Edwards \& Roberts, 2009). Both extremes reduce LE (whether across or within nations) and evidence consistently converges on a more moderated peak of food consumption that matches past laboratory studies informing the dietary recommendations of the UNFAO (2010). More equitable distribution of food (as just one example) would go a long way towards enhancing LE in both developed and developing nations whilst simultaneously reducing $\mathrm{CE}$ against the unhealthy consumption goals pursued among developed nations. This and other curves should be more fully explored using frontier regression.

Much work is yet to be done to explore the underlying reasons for the CE curve and its long-run stability across many other different indices of significance to the MDGs and their feasibility across nations. One issue resides in whether the empirical optimum can be pursued by many different countries affected by different geographic, economic and socio-cultural circumstances, which is possibly more suited to DEA. Moreover, preliminary work testing the curve within nations across 
time already suggests the effects of carbonised growth are inconsistent when applied to LE, although this is ameliorated when time-lags of up to a decade are controlled for. Another work in progress uses an adapted form of $\alpha$-trimmed sampling to simultaneously equalise sample sizes across development whilst eliminating the effects of outliers and time lags.

In the meantime, the present study suggests a lower $C \& C$ target might be within reach. Putting aside issues of causality and national adaptability, we can generously estimate what might be possible for countries under different climate budgets. From 2050 onwards, Meinshausen and colleagues (2009) allow an annual budget of 3.1Gt to accommodate 9 billion people in 2050 and 10 billion in 2100 (conservatively, UN, 2011). This allows for a global target of only $0.33 \mathrm{CE} / \mathrm{cap}$ in 2050 falling to $0.30 \mathrm{CE} / \mathrm{cap}$ in 2100 . Even if the smaller budget is applied as early as 2050, the frontier curve in this study might still offer a more optimistic outcome with no average global loss in LE, even when using the highest CE in 2005 (8.9 CE/cap). It still requires an ideal and adaptable world where wealthier countries reduce emissions and poorer countries pursue a development trajectory that is more sustainable and possibly much healthier. The climate science will demand action on the C\&C target as soon as possible if we are to achieve any sort of equitable balance in a carbon-constrained future. This paper suggests a moderate $C \& C$ target might be a first step towards balancing the competing demands of both international and intergenerational equity.

Footnote: since going to press, COP 18 suggests the $2^{\circ} \mathrm{C}$ limit has been surpassed and the world is heading towards a $4-6^{\circ} \mathrm{C}$ increase in global temperatures, making agreement on the $\mathrm{C} \& \mathrm{C}$ target described in this paper, or lower, more urgent than ever before.

\section{REFERENCES}

Abdallah, S., Thompson, S., Michaelson, J., Marks, N., Steuer, N.et alia (2009). The Happy Planet Index 2.0. London: New Economics Foundation.

Aigner, D \& Chu, S (1968). On Estimating the Industry Production Function. American Economic Review, 58, 826-839.

Bloomberg, M \& Aggarwala, R (2008) Think Locally, Act Globally: How Curbing Global Warming Emissions Can Improve Local Public Health . Am J Preventive Med 35(5) 414-423

Bradshaw, J, Hoelscherb, P \& Richardson, D (2007) Comparing Child Well-Being in OECD Countries: Concepts and Methods. Innocenti Working Paper No 2006-03. Florence, UNICEF Innocenti Research Centre.

Brickman, P \& Campbell, D (1971) Hedonic Relativism and Planning the Good Society. Apley, M (1971) (Ed) Adaptation Level Theory: A Symposium, pp 287-302. New York: Academic Press.

Brundtland Commission (1987) Our Common Future. New York: Oxford University Press.

Cantril H (1965) The pattern of human concern. New Brunswick, NJ: Rutgers University Press.

Carlsen, H, Gislasen, Benediktsdottir, B, Kolbeinsson, T, Hauksdottir, A, Throstur Thorsteinsson, T \& Briem, H (2012) A survey of early health effects of the Eyjafjallajökull 2010 eruption in Iceland: a population-based study. BMJ Open 2012;2:e000343doi:10.1136/bmjopen-2011-000343. http://bmjopen.bmj.com/content/2/2/e000343.full

Coelli, T.J., Prasada Rao, D.S., O'Donnell, C.J. and Battese, G.E. (2005), An. Introduction to Efficiency and Productivity Analysis, 2nd Edition, Springer: New York.

CSDH (2008) Closing the gap in a generation: health equity through action on the social determinants of health. Final Report of the Commission on Social Determinants of Health. Geneva: World Health Organization.

Diener, E, Sandvik, E, Seidlitz, L \& Diener, M (1993) The Relationship Between Income \& Subjective Wellbeing: Relative or Absolute? Soc Ind Res, 28, pp 195-223 
Diener, E \& Suh, E (2000) Culture \& Subjective Wellbeing. Massachusetts: MIT.

Duesenberry, J (1949).Income, Saving and the Theory of Consumer Behaviour. Cambridge, MS: Harvard University Press.

Easterlin, R (1974) Does Economic Growth Improve the Human Lot? Some Empirical Evidence. In: David, P \& Reder, M (1974) (Eds) Nations and Households in Economic Growth: Essays in Honor of Moses Abramowitz. New York: Academic Press. http://graphics8.nytimes.com/images/2008/04/16/business/Easterlin1974.pdf

Easterlin, R (2005) Diminishing Marginal Utility of Income? Caveat Emptor. Social Indicators Research, 70(3), pp243-255

Eckersley R. 2006. Progress, sustainability and human wellbeing: Is a new worldview emerging? International Journal of Innovation and Sustainable Development, vol. 1, no.4, pp. 306-317.

Edwards, P \& Roberts R (2010) Population adiposity and climate change. Int. J. Epidemiol, 39(5).

Ekins, P, Meyer, B \& Shmidt-Bleek, F (2009) Reducing Resource Consumption: A Proposal for Global Resource and Environmental Policy. GWS Discussion Paper 2009/5 ISSN 1867-7290. Osnabrück: Gesellschaft für Wirtschaftliche Strukturforschung $\mathrm{mbH}$.

Evans, David B., Ajay Tandon, Christopher J.L. Murray and Jeremy A. Lauer (2000). The comparative efficiency of national health systems in producing health: An analysis of 191 countries. GPE Discussion Paper 29, World Health Organization, Geneva.

Farrell, M (1957) The Measurement of Productive Efficiency. J Royal Stat Society, 120, pp 253-281

Fitoussi, J-P, Sen, A \& Stiglitz, J (2010) Mismeasuring Our Lives: Why GDP Doesn't Add Up. The Report by the Commission on the Measurement of Economic Performance and Social Progress. London: The New Press.

Folbre, N (2008) Valuing Children: Rethinking the Economics of the Family. Cambridge, MS: Harvard University Press,

Frey, B \& Stutzer, A (2002) Happiness and Economics: How the Economy and Institutions Affect Well-Being. Princeton: Princeton University Press.

Frumkin, H, McMichael, A \& Hess, J (2008) Climate Change and the Health of the Public . Am J Preventive Med 35(5) 401402

Gallup (2006) The World Poll Questionnaire. http://media.gallup.com/dataviz/www/WP_Questions_WHITE.pdf. For more information on Gallup's methodology see www.gallup.com/consulting/worldpoll/24046/About.aspx.

Garnaut, R. (2011) Progress towards effective global action on climate change. Garnaut Climate Change Review, Update Paper Number 2. http://www.garnautreview.org.au/update-2011/update-papers/up2-progress-towards-effective-globalaction-climate-change.html

Global Commons Institute (GCI) (1996) Draft Proposals for a Climate Change Protocol based on Contraction and Convergence. London, UK. http://www.gci.org.uk/contconv/cc.html.

Gullone, E \& Cummins, R (Eds) (2002) The Universality of Subjective wellbeing Indicators: A Multidiscplinary and Multinational Perspective. Social Indicators Research Series, Volume 16. Netherlands: Kluwer Academic

Publishers.Hamilton, C \& Denniss, R (2005) 09099. Sydney: Allen \& Unwin.

Hamilton, C \& Denniss, R (2005) Affluenza: When Too Much is Never Enough. Sydney: Allen \& Unwin.

Hansen, J, Sato, M, Kharecha, P, Beerling, D, Masson-Delmotte, V, Pagani, M, Raymo, M, Royer, D \& Zachos, J (2008) Target Atmospheric CO2: Where Should Humanity Aim? The Open Atmospheric Science Journal, 2008, 2, 217-231. http://www.columbia.edu/ jeh1/2008/TargetCO2_20080407.pdf

Hansen, J.E. (2009). Storms of My Grandchildren: The Truth About the Coming Climate Catastrophe and Our Last Chance to Save Humanity. New York: Bloomsbury Press.

Hare, B \& Meinshausen, M (2006) How much warming are we committed to and how much can be avoided? Climate Change, 75(1-2), pp111-149

Haq, M (1995) Reflections on Human Development. New York: Oxford University Press. 
Human Mortality Database (2011) University of California, Berkeley (USA), and Max Planck Institute for Demographic Research (Germany). Available at www.mortality.org/cgi-bin/hmd/hmd_download.php (data downloaded on 1 December, 2011)

Inglehart, R (1997) Modernisation \& Postmodernisation: Cultural, Economic \& Political Change in 43 Societies. Princeton, NJ: Princeton University Press.

International Energy Agency (2010) CO2 Emissions from Fuel Combustion Highlights. 2010 Edition. Paris: OECD/International Energy Agency. http://www.iea.org/co2highlights/co2highlights.pdf

International Energy Agency (2012) Global carbon-dioxide emissions increase by $1.0 \mathrm{GT}$ in 2011 to record high. IEA Newsroom, 24 May 2012; http://www.iea.org/newsroomandevents/news/2012/may/name,27216,en.html

Jackson, T (2009) Prosperity without growth: Economics for a Finite Planet. London: Earthscan.

Jayasuriya, R \& Quentin Wodon, Q (2003). Efficiency in Reaching the Millennium Development Goals, World Bank, Washington DC.

Jotzo, F, Burke, P, Wood, P, Macintosh, A \& Stern, D (2012) Decomposing the 2010 global carbon dioxide emissions rebound. Nature Climate Change, 2, pp 213-214.

Lopez, A, Mathers, C, Ezzati, M, Jamison, D \& Murray, C (2006) Global and regional burden of disease and risk factors, 2001: systematic analysis of population health data. The Lancet, 367, pp 1747-57. http://www.fic.nih.gov/news/fogarty/2006/dcpp_lancet_367.pdf

Magnus, G (2009) The Age of Aging: How Demographics are Changing the Global Economy and Our World. Singapore: John Wiley \& Sons (Asia) Pte Ltd

Malcolm, J.R., C.R. Liu, R.P, Neilson, et al. (2006) Global warming and extinctions of endemic species from biodiversity hotspots, Conservation Biology 20: $538-548$

Marks, N., Abdallah, S., Simms, A., Thompson, S.et alia (2006).The Happy Planet Index 1.0. London: New Economics Foundation.

Max-Neef, M (1995) Economic growth and quality of life. Ecological Economics, 15, pp 115-118

McGray, H. (2010) From Copenhagen to Cancun: Adaptation. Washington, DC: World Resources Institute. In http://www.wri.org/stories/2010/05/copenhagen-cancun-adaptation.

Meinshausen, M, Meinshausen, N, Hare, W, Raper, S, Frieler, K, Knutti, R, Frame, D Allen, M (2009) Greenhouse-gas emission targets for limiting global warming to $2^{\circ} \mathrm{C}$. Nature $458,1158-1162$.

http://www.nature.com/nature/journal/v458/n7242/abs/nature08017.html

Meyer, A \& O'Connell, T (2010) Copenhagen blame game sparked by failure to properly explain Danish Text. Business Green Sustainable Thinking, 11 January 2010. http://www.businessgreen.com/bg/opinion/1807635/copenhagen-blamegame-sparked-failure-properly-explain-danish-text

Murray, C \& Lopez , A (Eds) (1996) The global burden of disease: a comprehensive assessment of mortality and disability from diseases, injuries, and risk factors in 1990 and projected to 2020. Cambridge (MA): Harvard University Press.

Nordhaus, W (2007) The Stern Review on the Economics of Climate Change. May 3, 2007. Yale: http://nordhaus.econ.yale.edu/stern_050307.pdf

Oswald, A (2005) On the Common Claim that Happiness Equations Demonstrate Diminishing Marginal Utility of Income. Warwick University, UK.

Parry, M.L, C. Rosenzweig, A. Iglesias et al. (2004) Effects of climate change on global food production under SRES emissions and socio-economic scenarios, Global Environmental Change 14: $53-67$

Preston, S. H (1975). "The Changing Relation between Mortality and Level of Economic Development". Population Studies 29 (2): 231. http://www.jstor.org/pss/2173509.

Robinson, J (1962) Economic Philosophy. Harmondsworth, Middlesex, UK: Penguin Books Ltd. 
Rosa, E, York, R \& Dietz, T (2004) Tracking the Anthropogenic Drivers of Ecological Impacts. AMBIO: A Journal of the Human Environment 33, pp 509-512.

Schmidt-Bleek, F. (2009) The Earth: Natural Resources and Human Intervention. London: Haus Publishers.

Seiford, L \& Thrall , R (1990) Recent Developments in DEA: The Mathematical Programming Approach to Frontier Analysis, J Econometrics, 6: pp.7-38.

Sen, A (1981). Public action and the quality of life in developing countries, Oxford Bulletin of Economics and Statistics, 43, 287-319.

Sen, A (1999) Development as Freedom. Oxford: Oxford University Press.

Sherwood, S \& Huber, M (2010) An Adaptability Limit to Climate Change Due to Heat Stress. Proceedings of the National Academy of Sciences of the United States of America. Published online before print May 3, 2010, doi: 10.1073/pnas.0913352107 PNAS May 3, 2010; http://www.pnas.org/content/early/2010/04/26/0913352107.full.pdf+html

Steckel, R (1983) Height and Per Capita Income. Historical Methods 16(1), pp1-7

Steinberger, J, Roberts, J, Peters, G \& Baiocci, G (2012) Pathways of human development and carbon emissions embodied in trade. Nature Climate Change, doi:10.1038/nclimate1371, Published online: 22 January 2012;

http://www.nature.com/nclimate/journal/vaop/ncurrent/full/nclimate1371.html

Stern, D (2004) The Rise and Fall of the Environmental Kuznets Curve. World Development 32(8), 1419-1439.

http://anu.academia.edu/DavidStern/Papers/732338/The_rise_and_fall_of_the_environmental_Kuznets_curve

Stern, N. (2006). Stern Review on The Economics of Climate Change (pre-publication edition). Executive Summary. HM Treasury, London. http://www.webcitation.org/5nCeyEYJr.

Stern, N. (2008): The Economics of Climate Change. American Economic Review. Papers and Proceedings, 98(2), pp 1-37. http://www.rasmusen.org/g406/readings-old/11.global.warming.pdf

Stevenson, B \& Wolfers, J (2009) The Paradox of Declining Female Happiness. American Economic Journal: Economic Policy, American Economic Association, 1(2), pp 190-225

Sutton, P (2003) An Empirical Environmental Sustainability Index Derived Solely from Nighttime Satellite Imagery and Ecosystem Service Valuation. Population \& Environment, 24(4), pp 293-311.

Sutton, P, Anderson,S, Elvidge, C, Tuttle, B \& Ghosh, T (2009) Paving the Planet: Impervious Surface as Proxy Measure of the Human Ecological Footprint. Progress in Physical Geography 33(4), pp 510-527.

Thomas, C.D., A. Cameron, R.E. Green et al. (2004a) Extinction risk from climate change, Nature 427: 145 - 148

Thornton, P. (2012) Recalibrating Food Production in the Developing World: Global Warming Will Change More Than Just the Climate. CCAFS Policy Brief no. 6. (CGIAR Research Program on Climate Change, Agriculture and Food Security, 2012).

Troutt, M, Hu, M, Shanker, M \& Acar W (2001) Frontier Versus Ordinary Regression Models for Data Mining. In: Pendharker, P (2003) Managing Data Mining Technologies in Organizations: Techniques and Applications. IGP: PA. See: http://www.personal.kent.edu/ mshanker/personal/Zip_files/FrontierChapter.pdf

United Nations Food \& Agriculture Organization (2010) The State of Food Insecurity in the World: Addressing Food Insecurity in Protracted Crises. Rome: UNFAO. http://www.fao.org/docrep/013/i1683e/i1683e.pdf

United Nations Population Division (2009) World Population Prospects: The 2008 Revision. New York, United Nations, Department of Economic and Social Affair Catalogue Sources World Development Indicators.

http://data.worldbank.org/indicator/SP.DYN.LEOO.IN

United Nations Population Division (2011) World Population Prospects: The 2010 Revision. New York, United Nations, Department of Economic and Social Affair Catalogue Sources World Development Indicators. http://esa.un.org/unpd/wpp/index.htm

United States Carbon Dioxide Information Analysis Center (2009) Environmental Sciences Division, Oak Ridge National Laboratory, Tennessee, United States. Catalogue Sources World Development Indicators. For the full dataset, see: http://data.worldbank.org/indicator/EN.ATM.CO2E.PC 
Veenhoven, R (1996) Happy Life Expectancy - A Comprehensive Measure Of Quality Of Life In Nations. Social Indicators Research, 39, pp 1-58.

Vermeulen, S., Campbell, B. \& Ingram, J (2012) Climate Change \& Food Systems. Ann. Re. Environ. Resources, 37, pp 195222

Wackernagel, M \& Rees, W (1996) Our Ecological Footprint: Reducing Human Impact on the Earth. Gabriola Island, BC: New Society Publishers.

World Bank Report (1993) Investing in Health. Oxford: Oxford University Press.

World Health Organization (2000) Nutrition for Health \& Development: A Global Agenda for Combating Malnutrition. France: WHO. http://whqlibdoc.who.int/hq/2000/WHO_NHD_00.6.pdf

York, R, Rosa, E \& Dietz, T (2003) Footprints on the Earth: The Environmental Consequences of Modernity. American Sociological Review, 68, pp 279-300.

Zolatas, X (1981) Economic Growth and Declining Social Welfare. New York: New York University Press.

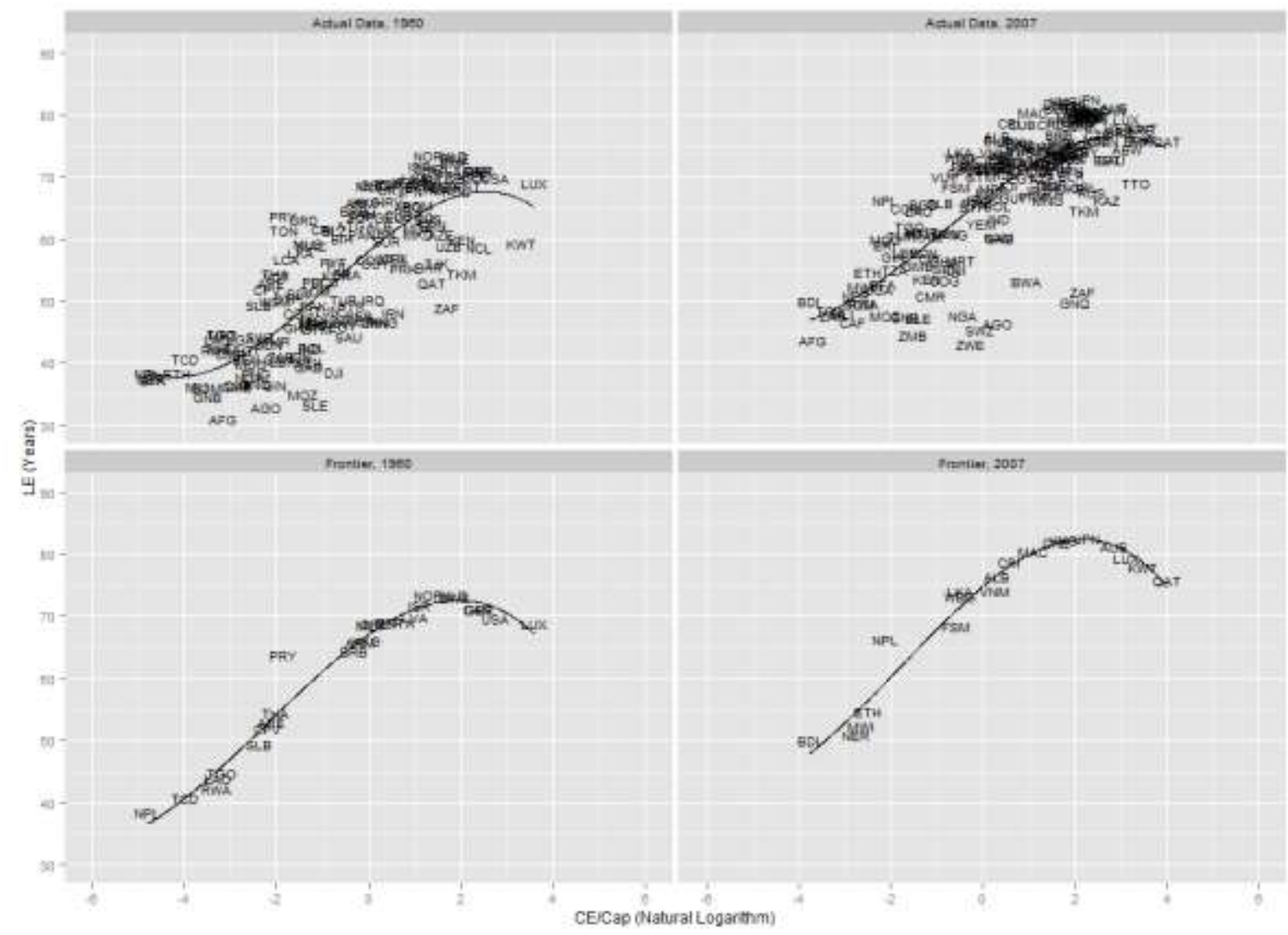




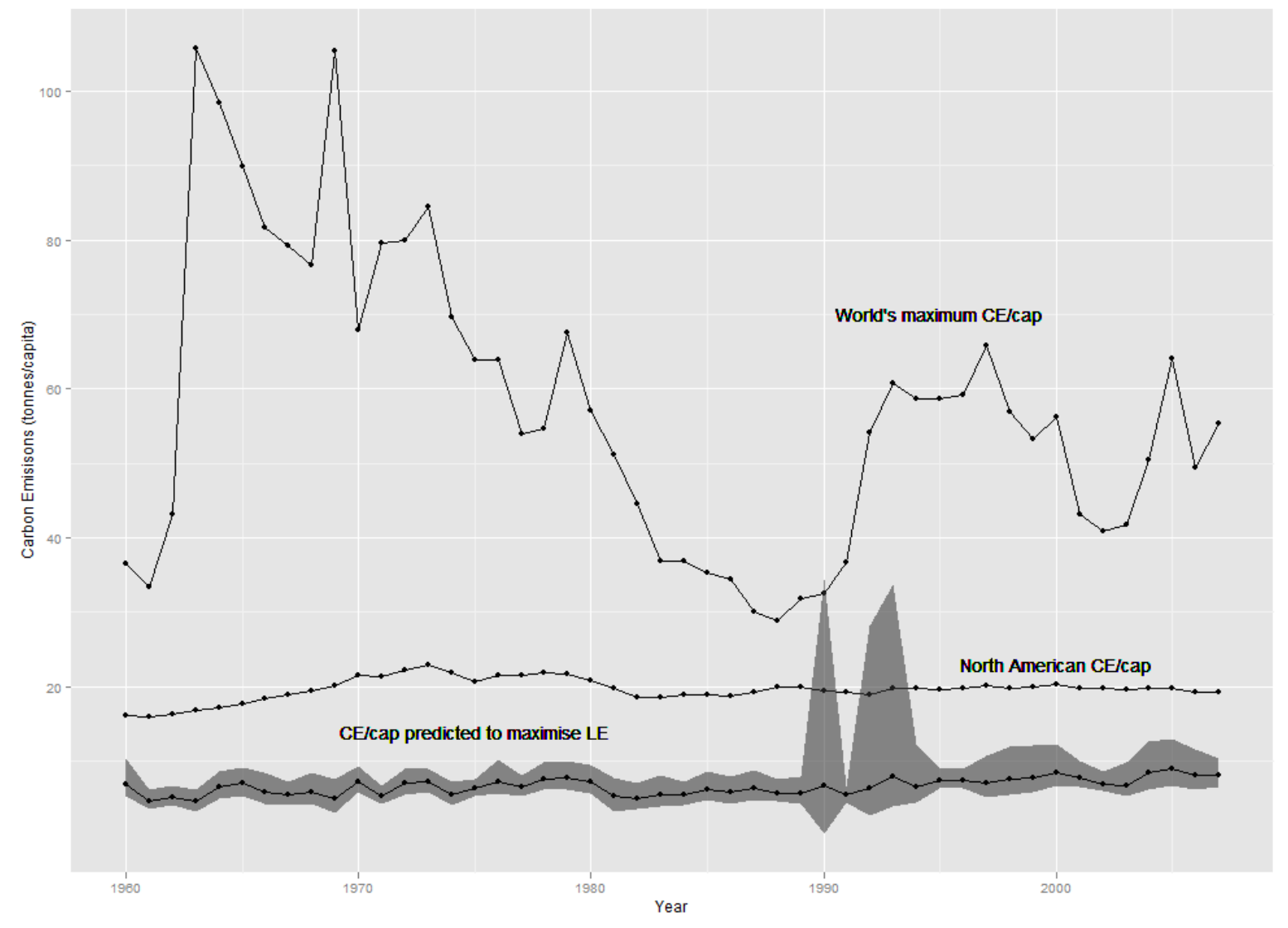




\section{University Library}

\section{- M M N E R VA A gateway to Melbourne's research publications}

Minerva Access is the Institutional Repository of The University of Melbourne

Author/s:

Read, PA;Stanley, JR;Vella-Brodrick, DA;Griggs, DJ

Title:

Towards a contraction and convergence target based on population life expectancies since 1960

Date:

2013-10-01

Citation:

Read, P. A., Stanley, J. R., Vella-Brodrick, D. A. \& Griggs, D. J. (2013). Towards a contraction and convergence target based on population life expectancies since 1960.

Environment, Development and Sustainability, 15 (5), pp.1173-1187. https://doi.org/10.1007/ s10668-012-9432-y.

Persistent Link:

http://hdl.handle.net/11343/282585 